\title{
Impact of acute renal failure on plasmatic levels of cleaved endocan
}

\author{
Alexandre Gaudet ${ }^{1,2,3,4^{*}}$ (D), Erika Parmentier ${ }^{1,2,3,4}$, Nathalie De Freitas Caires ${ }^{1,2,3,5}$, Lucie Portier ${ }^{1,2,3,5}$, \\ Sylvain Dubucquoi ${ }^{6}$, Julien Poissy ${ }^{4}$, Thibault Duburcq ${ }^{4}$, Maxence Hureau ${ }^{1,2,3,4}$, Philippe Lassalle ${ }^{1,2,3,7}$ and \\ Daniel Mathieu ${ }^{1,2,3,4}$
}

\section{Dear Editor,}

Recent failures to improve the prognostic of sepsis have underlined the need for a better phenotypical description of septic subjects. In this view, endocan, an endothelial proteoglycan secreted under proinflammatory conditions, has been described as a useful biomarker to early identify patients at higher risk of poor outcomes during the time course of sepsis [1]. More recently, a major catabolite of endocan, p14, has been observed at high plasmatic levels in a series of septic subjects, paving the way for a more accurate prediction of poor outcomes in such patients. However, major variations of p14 were observed between patients in this series, with unknown clinical significance [2]. Furthermore, it is currently unknown whether p14 could undergo renal elimination.

We performed a post hoc analysis based on the data from a previously published prospective cohort of severe septic patients [3]. Ninety-nine patients underwent measurement of p14 on EDTA plasma. Plasmatic endocan cleavage ratio (ECR) was calculated as plasma $\mathrm{p} 14 /($ endocan $+\mathrm{p} 14)$ ratio (endocan and $\mathrm{p} 14$ being expressed in $\mathrm{pmol} / \mathrm{mL}$ ) on baseline and $24 \mathrm{~h}, 48$ $\mathrm{h}$, and $72 \mathrm{~h}$ following ICU admission. Baseline characteristics of patients are exposed in Additional file 1.

In this cohort, ECR on enrolment was correlated with baseline SAPS $2\left(\rho=0.36,95 \%\right.$ CI $\left.(0.17-0.53) ; p<10^{-3}\right)$ and SOFA $(\rho=0.21(0-0.39) ; p=0.04)$. Renal SOFA was the only component of SOFA score associated with higher ECR, with median [IQR] baseline ECR observed at 0.38 [0.29-0.61] in patients with baseline renal SOFA $>2$ vs $0.28[0.19-0.36]$ in patients with baseline renal SOFA $\leq 2\left(p<10^{-3}\right)$ (Table 1). Over $72 \mathrm{~h}$, patients with a baseline renal SOFA at 4 had higher median plasmatic ECR than those with baseline renal SOFA $<4\left(p<10^{-3}\right)$ (Fig. 1).

Our results suggest that circulating concentrations of p14 might be influenced by the severity of acute renal failure. Therefore, it could be proposed that, by contrast with endocan, p14 could be eliminated through glomerular filtration, thus suggesting that it should be measured in urine rather that in blood. This discrepancy might be explained by the smaller molecular weight of p14, as well as the absence of polyanionic glycanic chain on its protein core. Further explorations are needed to confirm these hypotheses.

* Correspondence: alexandre.gaudet@chru-lille.fr

${ }^{1}$ Univ. Lille, U1019 - UMR 8204 - CIIL - Center for Infection and Immunity of Lille, F-59000 Lille, France

${ }^{2}$ CNRS, UMR 8204, F-59000 Lille, France

Full list of author information is available at the end of the article

(c) The Author(s). 2019 Open Access This article is distributed under the terms of the Creative Commons Attribution 4.0 International License (http://creativecommons.org/licenses/by/4.0/), which permits unrestricted use, distribution, and reproduction in any medium, provided you give appropriate credit to the original author(s) and the source, provide a link to the Creative Commons license, and indicate if changes were made. The Creative Commons Public Domain Dedication waiver (http://creativecommons.org/publicdomain/zero/1.0/) applies to the data made available in this article, unless otherwise stated. 
Table 1 Endocan cleavage ratio (ECR) according to patients' characteristics

\begin{tabular}{|c|c|c|c|c|}
\hline Variables & Absent & Present & Spearman $\rho(95 \% \mathrm{Cl})$ & $p$ \\
\hline Age (years) & & & $0.18(-0.03-0.37)$ & 0.08 \\
\hline \multicolumn{5}{|l|}{ Chronic comorbidities } \\
\hline COPD & $0.33[0.21-0.42]$ & $0.23[0.18-0.51]$ & & 0.53 \\
\hline Smoker & $0.33[0.21-0.45]$ & $0.23[0.18-0.35]$ & & 0.15 \\
\hline Cardiomyopathy & $0.3[0.2-0.42]$ & $0.33[0.2-0.45]$ & & 0.61 \\
\hline Chronic kidney failure & $0.31[0.21-0.44]$ & $0.25[0.05-0.56]$ & & 0.7 \\
\hline Cirrhosis & $0.31[0.2-0.45]$ & $0.3[0.21-0.37]$ & & 0.63 \\
\hline \multicolumn{5}{|l|}{ Sepsis severity on enrolment } \\
\hline Severe sepsis & & $0.29[0.2-0.41]$ & & \\
\hline Septic shock & & $0.31[0.2-0.45]$ & & 0.74 \\
\hline \multicolumn{5}{|l|}{ Site of infection on enrolment } \\
\hline Soft tissues & & $0.3[0.2-0.39]$ & & \\
\hline Respiratory & & $0.33[0.21-0.45]$ & & \\
\hline Urinary & & $0.31[0.22-0.53]$ & & 0.82 \\
\hline Digestive & & $0.31[0.24-0.38]$ & & \\
\hline Other & & $0.21[0.07-0.49]$ & & \\
\hline \multicolumn{5}{|l|}{ Biomarkers on enrolment } \\
\hline $\mathrm{CRP}(\mathrm{mg} / \mathrm{L})$ & & & $0(-0.21-0.2)$ & 0.96 \\
\hline $\mathrm{PCT}(\mathrm{ng} / \mathrm{mL})$ & & & $0.06(-0.15-0.26)$ & 0.58 \\
\hline \multicolumn{5}{|l|}{ Prognostic scores on enrolment } \\
\hline SAPS 2 & & & $0.36(0.17-0.53)$ & $<10^{-3}$ \\
\hline SOFA & & & $0.21(0-0.39)$ & 0.04 \\
\hline LIPS & & & $0.12(-0.08-0.32)$ & 0.22 \\
\hline \multicolumn{5}{|l|}{ Organ SOFA > 2 on enrolment } \\
\hline Pulmonary & $0.3[0.2-0.37]$ & $0.35[0.24-0.48]$ & & 0.19 \\
\hline Renal & $0.28[0.19-0.36]$ & $0.38[0.29-0.61]$ & & $<10^{-3}$ \\
\hline Hepatic & $0.32[0.21-0.42]$ & $0.26[0.14-0.53]$ & & 0.75 \\
\hline Circulatory & $0.23[0-0.39]$ & $0.33[0.23-0.45]$ & & 0.12 \\
\hline Neurological & $0.3[0.2-0.38]$ & $0.33[0.24-0.48]$ & & 0.19 \\
\hline Hematological & $0.31[0.2-0.4]$ & $0.27[0.12-0.54]$ & & 0.99 \\
\hline \multicolumn{5}{|l|}{ Mortality } \\
\hline Day 28 & $0.3[0.19-0.38]$ & $0.33[0.23-0.48]$ & & 0.4 \\
\hline ICU discharge & $0.3[0.2-0.37]$ & $0.33[0.23-0.54]$ & & 0.24 \\
\hline ICU length of stay (days) & & & $0.16(-0.04-0.35)$ & 0.11 \\
\hline Mechanical ventilation on enrolment & $0.3[0.19-0.37]$ & $0.31[0.23-0.47]$ & & 0.33 \\
\hline
\end{tabular}

ECR are presented as median [IQR] values according to presence or absence of categorical variables. A Mann-Whitney test was used for comparison between two groups. A Kruskal-Wallis test was used for comparison between three or more groups. Correlations between ECR and continuous variables are described through Spearman $\rho(95 \% \mathrm{Cl})$

COPD chronic obstructive pulmonary disease, SOFA Sequential Organ Failure Assessment, ICU intensive care unit, SAPS 2 Simplified Acute Physiology Score 2, LIPS Lung Injury Prediction Score 



Fig. 1 a Box plots of plasmatic endocan cleavage ratio (ECR) on enrolment according to baseline renal SOFA. Box plot shows the median (horizontal line) and IQR (25th-75th percentile) (box). The whiskers show the lowest data within 1.5 IQR of the lower quartile and highest data within 1.5 IQR of the upper quartile; data outside $1.5 \mathrm{IQR}$ of the upper or lower quartiles are depicted with a dot. Comparison between subjects with renal SOFA $>2 \mathrm{vs}$ renal SOFA $\leq 2$ was performed with the Mann-Whitney test. ${ }^{*}: p<10^{-3}$. b Kinetics of plasmatic ECR median values over $72 \mathrm{~h}$ following enrolment according to baseline renal SOFA

\section{Additional file}

Additional file 1: Cohort baseline characteristics. Continuous and categorical variables are described as median [interquartile range] and number (percentage), respectively. COPD chronic obstructive pulmonary disease, SOFA Sequential Organ Failure Assessment, ICU Intensive Care Unit SAPS 2 Simplified Acute Physiology Score 2, LIPS Lung Injury Prediction Score (DOC 45 kb)

\section{Abbreviations}

ECR: Endocan cleavage ratio

\section{Acknowledgements}

Not applicable.

\section{Funding}

This work was supported by BPI France (grant number BPI 2012-05-336). This funding was attributed to D. M, representing Lille University Hospital. There was no role of the funding body in the design of the study and collection, analysis, and interpretation of data and in writing the manuscript.

\section{Availability of data and materials}

The datasets used and/or analyzed during the current study are available from the corresponding author on reasonable request.

\section{Authors' contributions}

AG and EP designed the whole study, conducted the data analyses, and drafted the manuscript. ND, LP, and SD performed the biological measurements. DM supervised the whole project. All authors read and approved the final manuscript.

\section{Ethics approval and consent to participate}

This study has been approved by the ethics committee of Lille University Hospital (approval number CP03/07). All the participants to this study gave their informed consent prior to enrollment.

\section{Consent for publication}

Not applicable

\section{Competing interests}

The Endomark $\mathrm{H} 1$ and DIYEK C1 ELISA kits used in this study were provided by Lunginnov. PL is the cofounder of Lunginnov. ND and LP are staff members of Lunginnov. The remaining authors declare that they have no competing interests.

\section{Publisher's Note}

Springer Nature remains neutral with regard to jurisdictional claims in published maps and institutional affiliations.

\section{Author details}

${ }^{1}$ Univ. Lille, U1019 - UMR 8204 - CIIL - Center for Infection and Immunity of Lille, F-59000 Lille, France. ${ }^{2}$ CNRS, UMR 8204, F-59000 Lille, France. ${ }^{3}$ INSERM, U1019, F-59000 Lille, France. ${ }^{4} \mathrm{CHU}$ Lille, Pôle de Réanimation, Hôpital Roger Salengro, F-59000 Lille, France. ${ }^{5}$ Lunginnov, 1 rue du Pr Calmette, F-59000 Lille, France. ${ }^{6} \mathrm{CHU}$ Lille, Institut d'Immunologie, Centre de Biologie Pathologie Génétique, F-59000 Lille, France. ' Institut Pasteur de Lille, F-59000 Lille, France.

Received: 24 January 2019 Accepted: 7 February 2019

Published online: 19 February 2019

\section{References}

1. De Freitas Caires N, Gaudet A, Portier L, Tsicopoulos A, Mathieu D, Lassalle $P$. Endocan, sepsis, pneumonia, and acute respiratory distress syndrome. Crit Care Lond Engl. 2018;22:280

2. De Freitas Caires N, Legendre B, Parmentier E, Scherpereel A, Tsicopoulos A, Mathieu $\mathrm{D}$, et al. Identification of a $14 \mathrm{kDa}$ endocan fragment generated by cathepsin G, a novel circulating biomarker in patients with sepsis. J Pharm Biomed Anal. 2013:78-79:45-51.

3. Gaudet A, Parmentier E, Dubucquoi S, Poissy J, Duburcq T, Lassalle P, et al. Low endocan levels are predictive of acute respiratory distress syndrome in severe sepsis and septic shock. J Crit Care. 2018;47:121-6. 